\title{
Clinical and tumor significance of tropomyosin-1 expression levels in renal cell carcinoma
}

\author{
JIN WANG $^{1,2}$, JINGJING GUAN ${ }^{1}$, ZHIHUA LU $^{1}$, JINGJI JIN ${ }^{2}$, YONG CAI $^{2}$, \\ $\mathrm{CHUNXI} W A N G^{1}$ and FEI WANG ${ }^{2}$ \\ ${ }^{1}$ Department of Urology, The First Bethune Hospital of Jilin University, Changchun, Jilin 130021; \\ ${ }^{2}$ Epigenetics Laboratory, School of Life Science, Jilin University, Changchun, Jilin 130012, P.R. China
}

Received September 15, 2014; Accepted November 28, 2014

DOI: $10.3892 /$ or.2015.3733

\begin{abstract}
Renal cell carcinoma (RCC) is the most common type of kidney cancer in adults and has been described as one of the deadliest of cancers affecting the genitourinary tract. Tropomyosin is a two-stranded $\alpha$-helical coiled coil protein found in cell cytoskeletons. One of its isoforms, tropomyosin-1 (TPM1) has been reported as a novel tumor-suppressor gene and is downregulated in many solid tumors. However the expression level and function of TPM1 in RCC have not yet been determined. In the present study, we evaluated the TPM1-4 mRNA and TPM1 protein levels in RCC tissue samples. TPM1-overexpressing OSRC-2 and 786-O cell lines were also used to investigate the impact of TPM1 on RCC cells. We found that TPM1 was significantly and specifically downregulated in the RCC tissues. TPM1 expression was associated with tumor size, smoking status, Fuhrman grade and the prognosis of RCC patients. After TPM1 transfection, the migratory and invasive abilities of the OSRC-2 and 786-O cell lines were both reduced when compared to the control groups. Meanwhile, apoptosis was also enhanced in these two RCC cell lines following TPM1 transfection. Taken together, TPM1 exhibits characteristics of a tumor-suppressor gene while being overexpressed in RCC cell lines.
\end{abstract}

\section{Introduction}

Renal cell carcinoma ( $\mathrm{RCC}$ ), which originates from renal tubular epithelial cells, accounts for $80-85 \%$ of all cases of kidney cancer, and is responsible for $\sim 2-3 \%$ of all malignant

Correspondence to: Professor Chunxi Wang, Department of Urology, The First Bethune Hospital of Jilin University, Changchun, Jilin 130021, P.R. China

E-mail: chunxi_wang@126.com

Dr Fei Wang, Epigenetics Laboratory, School of Life Science, Jilin University, Changchun, Jilin 130012, P.R. China

E-mail: fei@jlu.edu.cn

Key words: renal cell carcinoma, tropomyosin, tumor suppressor, prognosis diseases in adults (1). The overall 5-year survival of RCC is as low as $20-25 \%$, and the most important factor in the selection of the appropriate therapy for RCC patients is the presence of metastases (2).

Tropomyosin (TPM) is an important component of microfilaments, a cytoskeleton structure, and is mainly involved in the contraction of skeletal and smooth muscle cells or maintaining the stability of the cytoskeleton in non-muscular cells (3). Four tropomyosin genes, TPM1, TPM2, TPM3 and TPM4, have been confirmed in mammals including humans. More than 20 isoforms can be produced through alternative splicing. All of these homologous isoforms fold into two parallel, linear chains of spiral $\alpha$-helices (4). These TPM proteins are involved in the regulation of many benign myopathies, such as myasthenia gravis and familial hypertrophic cardiomyopathy (5). Additionally, other studies have discovered that TPM1 plays an important role as a tumor-suppressor gene (TSG) in tumor occurrence and progression $(6,7)$. Recently, evidence indicates that TPMI could be a novel target gene of microRNA-21 which was found to be upregulated in many different solid tumors, including RCC (8). However, whether or not TPM1 serves as a tumor-suppressor gene in RCC and is selectively downregulated during RCC development has not been determined. Therefore, in the present study, we investigated the expression level of TPM1 in a set of RCC tissue samples and further evaluated its tumor-suppressing activities in two RCC cell lines (786-O and OSRC-2).

\section{Materials and methods}

Tissue samples. Ninety-eight tissue samples including 49 primary RCC tissues and 49 paired tumor adjacent renal tissues from the same patients were collected between May 2009 and April 2013 at The First Bethune Hospital of Jilin University, Jilin, China. All the samples were immediately stored in liquid nitrogen vapor at $-196^{\circ} \mathrm{C}$. All tumor specimens contained more than $80 \%$ cancer tissue and few necrosis in some. Tumor adjacent renal tissues were obtained from the region $5 \mathrm{~cm}$ distant from the tumor location, which ensured the absence of any kidney lesions. The present study was approved by the Ethics Committee of The First Bethune Hospital of Jilin University, and consent forms were obtained from all participating patients. 
Cell culture. Human clear cell renal cell carcinoma (ccRCC) cell line 786-O (TCHu3), human RCC cell line OSRC-2 (TCHu40) and human non-tumorous embryonal kidney cell line HEK293T were purchased from the Cell Resource Center of Shanghai Life Science Institute (Shanghai, China). HEK293T and OSRC-2 cells were cultured and maintained in high glucose Dulbecco's modified Eagle's medium (DMEM; Gibco, Carlsbad, CA, USA), while 786-O cells were cultured in RPMI-1640 medium (Gibco), both media being supplemented with $10 \%$ fetal bovine serum (Gibco), $100 \mathrm{U} / \mathrm{ml}$ penicillin, $100 \mathrm{mg} / \mathrm{ml}$ streptomycin in a $5 \times 7 \mathrm{~cm}$ flask in a moist atmosphere containing $5 \% \mathrm{CO}_{2}$ at $37^{\circ} \mathrm{C}$ (Thermo Scientific, Waltham, MA, USA). Cultured cells used for extracting total RNA or proteins were harvested from 1 well of a 6 -well plate and lysed using TRIzol reagent (Life Invitrogen, Carlsbad, CA, USA) or precooling RIPA lysis buffer [150 $\mathrm{mM} \mathrm{NaCl}$, $50 \mathrm{mM}$ Tris- $\mathrm{HCl}$ (pH 7.4)], 0.25\% Na-deoxycholate, $1 \%$ Nonidet P-40, $1 \mathrm{mM}$ EDTA and protease inhibitor cocktail tablets (Roche, Penzberg, Germany). The methods of the cell culture were previously described (9).

Reverse transcription and quantitative real-time $P C R$ $(R T-q P C R)$. Total RNA was isolated using TRIzol reagent (Invitrogen, Carlsbad, CA, USA) and reverse transcribed to cDNA using PrimeScript ${ }^{\mathrm{TM}}$ reverse transcriptase (Takara, Dalian, China). The resulting cDNA was analyzed by RT-qPCR with a real-time PCR detector (Ilumina Eco; Ilumina, San Diego, CA, USA). RT-qPCR reactions were completed under the following conditions: the initial denaturation step consisted of $95^{\circ} \mathrm{C}$ for $30 \mathrm{sec}$, followed by 40 cycles of further denaturation at $95^{\circ} \mathrm{C}$ for $5 \mathrm{sec}$, and annealing and extension at $60^{\circ} \mathrm{C}\left(59^{\circ} \mathrm{C}\right.$ for TPM2, TPM3 and TPM4) for $30 \mathrm{sec}$. The following steps were used to obtain the melting curve: $95^{\circ} \mathrm{C}$ for $15 \mathrm{sec}$, then $55^{\circ} \mathrm{C}$ for $15 \mathrm{sec}$ and finally $95^{\circ} \mathrm{C}$ for $15 \mathrm{sec}$ again. The final concentration of all reagents in the reaction were as follows: SYBR ${ }^{\circledR}$ Premix Ex Taq $1 \mathrm{X}$, forward and reverse primers $0.2 \mu \mathrm{M}$ each, DNA templates $\leq 5 \mathrm{ng} / \mu 1$. Unless otherwise indicated, the relative mRNA expression levels were calculated as $-\Delta \Delta \mathrm{Ct}$ where $\Delta \Delta \mathrm{Ct}=\Delta \mathrm{Ct}_{\text {tumor }}-\Delta \mathrm{Ct}_{\text {normal }}$ and $\Delta \mathrm{Ct}=\mathrm{Ct}_{\text {target }}-\mathrm{Ct}_{\text {control }}$. TPM1-4 were the target genes, and $G A P D H$ was the control gene in the present study. Table I lists the primer sequences (synthesized by BGI Gene Company, Beijing, China) used for RT-qPCR.

Western blotting. Methods for the protein extraction and western blotting were previously described (9). Whole cell lysate from the cultured cells was mixed with 4X SDS loading buffer (8\% SDS, 30\% glycerol, $0.25 \mathrm{M}$ Tris- $\mathrm{HCl} \mathrm{pH} 6.8$, $0.02 \%$ bromophenol blue with $10 \% \mathrm{BME}$ ). Kidney tissue samples $(100 \mathrm{mg})$ were homogenized with tissue grinders (XinZhi, Ningbo, China) and solubilized in $100 \mu \mathrm{l}$ precooling RIPA lysis buffer. Whole cell lysate was prepared by sonication (Scientz-IID, Ningbo, China) for $12 \mathrm{sec}$ with $30 \%$ work cycle and following centrifugation at $15,000 \mathrm{x}$ g for $10 \mathrm{~min}$ at $4^{\circ} \mathrm{C}$. Total proteins in the supernatant after centrifugation were quantified using the Bradford method according to the handling manual (Bio-Rad, Hercules, CA, USA). Equal total amounts of boiled protein samples with SDS loading buffer were separated by SDS polyacrylamide gel (SDS-PAGE) electrophoresis, and specific proteins were detected by immu-
Table I. Primer sequences for the RT-qPCR.

\begin{tabular}{llc}
\hline $\begin{array}{l}\text { Primer } \\
\text { name }\end{array}$ & \multicolumn{1}{c}{ Sequence 5'-3' } & $\begin{array}{c}\text { Product } \\
\text { size (bp) }\end{array}$ \\
\hline GAPDH F & GAGCCACATCGCTCAGACAC & 150 \\
GAPDH R & CATGTAGTTGAGGTCAATGAAGG & \\
TPM1 F & GCCGACGTAGCTTCTCTGAAC & 160 \\
TPM1 R & TTTGGGCTCGACTCTCAATGA & \\
TPM2 F & TGAGACCCGAGCAGAGTTTG & 132 \\
TPM2 R & TTGAGTGCGTTGTCCAGTTC & \\
TPM3 F & AGGAGACTTGGAACGCACAG & 100 \\
TPM3 R & AGACTTGAGGTTGTTGGTGACA & \\
TPM4 F & ACCGCAAATACGAGGAGGTA & 118 \\
TPM4 R & TTGAGTTCTTCTTCCAGGTCAC & \\
\hline
\end{tabular}

F, forward; R, reverse.

noblotting using TPM1 (1:500, \#AV41392, rabbit anti-human polyclonal; Sigma-Aldrich, St. Louis, MO, USA) antibodies and $\alpha$-tubulin (1:800,\#bs-0159R, rabbit anti-human polyclonal; Bioss, Beijing, China) antibodies. Protein bands were analyzed by Quantity One ${ }^{\circledR}$ (Bio-Rad) and the TPM1 protein level was defined as the grey scale value ratio of TPM1 to $\alpha$-tubulin.

Immunohistochemical (IHC) staining. To obtain homogeneous samples for immunohistochemical analysis, we collected 25 formalin-fixed, paraffin-embedded tissue blocks from the 49 patients mentioned above. The method for immunohistochemical staining was previously described (9). Tissue blocks were sectioned and then heated in a constant temperature oven at $60^{\circ} \mathrm{C}$ for $3 \mathrm{~h}$. The sections were deparaffinized in xylene and rehydrated through a series of graded ethanol. The sections were washed by distilled water once then with phosphate-buffered saline (PBS) buffer twice every $3 \mathrm{~min}$. Each section was treated with $3 \%$ hydrogen peroxide solution at room temperature for $10 \mathrm{~min}$ to eliminate endogenous peroxidase. Then they were washed 3 times with PBS buffer, 5 min each time. The tissue sections were blocked with normal goat serum, incubated at room temperature for $15 \mathrm{~min}$, the serum was decanted, but not washed, and 1:100 dilution of TPM1 polyclonal antibodies (\#AV41392, rabbit anti-human; Sigma-Aldrich), was added and maintained at $4^{\circ} \mathrm{C}$ overnight. Tissue slides were washed by PBS buffer again and biotinylated secondary antibody was added at $37^{\circ} \mathrm{C}$ for $10 \mathrm{~min}$. Tissue sections were incubated in horseradish peroxidase-labeled streptavidin working solution at $37^{\circ} \mathrm{C}$ for $10 \mathrm{~min}$. Finally, the immunoreaction was detected using the DAB detection kit (Maixin, Fuzhou, China).

Semi-quantitation of IHC staining. The staining intensity (SI) and the percentage of positive cells (PP) were semi-quantitatively assessed using the following criteria: SI was scored as 0 , no staining; 1 , weak; 2 , moderate; and 3, strong; and PP: 0 , no positive cells; $1,<10 \% ; 2,10-50 \% ; 3,51-80 \%$; and $4,>80 \%$. For each section, the immunoreactive score (IRS) was calculated as SI x PP with a maximum possible value of 12 (10). 
Observations were recorded separately by two different individuals and the average score was used.

Plasmid transfection. The full-length coding sequence of the TPM1 gene transcription variant 5 was amplified from the HepG2 cell line cDNA library. Then the TPM1 coding sequence was linked into the $\mathrm{T}$ vector and finally constructed into the eukaryotic expression vector pcDNA3.1 to obtain the pcDNA3.1-TPM1 plasmid for cell transfection (Comate Bioscience, Changchun, China). HEK293T, 786-O and OSRC-2 cells were cultured in 6 -well plates $\left(1-2 \times 10^{5}\right.$ cells/ well) in specific complete culture medium as described above. These cells were transiently transfected with $0.2-1 \mu \mathrm{g}$ of pcDNA3.1-TPM1 plasmid using Lipofectamine ${ }^{\circledR} 2000$ reagent (Life Invitrogen) in the Opti-MEM ${ }^{\circledR}$ diluent condition (Gibco) following the manufacturer's instructions. Cells were harvested for further analysis $48 \mathrm{~h}$ after transfection.

Wound scratch assays. OSRC-2 and 786-O cells were seeded in a 6-well plate and incubated to form cell monolayers. Subsequently, cross-shaped scratches were made gently with sterile pipette tips across the diameter of the wells and washed with PBS to wipe off residuals. The scratched monolayers of cells were then transfected with different plasmid DNA. At least 5 microscopic (Olympus, Tokyo, Japan) fields were analyzed for each well at a magnification of x100 at 0,24 and $48 \mathrm{~h}$ after scratching (11). The ratio of the recovered area at 24 or $48 \mathrm{~h}$ after scratching to the initial wound area was identified as the wound healing rate.

Migration and invasion assays. OSRC-2 and 786-O cells were transfected with pcDNA3.1-NC or pcDNA3.1-TPM1 and starved for $24 \mathrm{~h}$. An in vitro Transwell ${ }^{\circledR}$ membrane (Corning Costar, Corning, NY, USA) precoated with BD Matrigel matrix (BD Biosiences, Franklin Lakes, NJ, USA) and medium mixture (matrix:medium, 1:1) was prepared for the overnight invasion assay and the uncoated membrane was prepped for the migration assay. The cell seeding amounts for this 24-well plate were $1 \times 10^{4}$ and $6 \times 10^{4}$ cells/well for the migration and invasion assay, respectively. Then culturing under the indicated condition for $24 \mathrm{~h}$ was carried out as described in the product instructions for users. Finally, the bottom filters were fixed in methanol and stained with $1 \%$ crystal violet solution. Images were captured for 5 random optical fields at x200 magnification on each filter.

Apoptosis assays. OSRC-2 and 786-O cells were transfected with pcDNA3.1-NC or pcDNA3.1-TPM1, or mock treated for 72 h. Cells were collected and stained with Annexin V-FLUOS staining kit (Roche) following the instructions for users. Sample cells were then analyzed by a FACS flow cytometer (Becton-Dickinson, Franklin Lakes, NJ, USA). We recorded Annexin V-positive and propidium iodide (PI)-negative cells as early stage apoptotic cells.

Statistical analysis. Statistical analysis was achieved using IBM SPSS ${ }^{\circledR}$ Statistics 21.0 (IBM, Armonk, NY, USA). Unless otherwise indicated, values are presented as the means \pm SEM. The paired t-test was used to determine significant differences between the treatment and the control groups. The Chi-square test was used to analyze the associations between TPM1 and clinical features. The log-rank test was used to analyze the survival results. Due to the marked dispersion of the cancer specimens, the Mann-Whitney $U$ test was performed to analyze RT-qPCR data instead of the t-test. Significance was defined at $\mathrm{p}<0.05$.

\section{Results}

Expression of TPM1, TPM2, TPM3 and TPM4 in the RCC tumor and paired adjacent normal renal tissues. The expression levels of four major TPM genes (TPM1, TPM2, TPM3 and TPM4) in the RCC tumor tissues and paired adjacent normal renal tissues from the same patients were detected by RT-qPCR. The mRNA levels of TPM2-4 had no significant differences in expression in the $33 \mathrm{RCC}$ tumor tissues compared to these levels in the adjacent normal renal tissues ( $\mathrm{p}=0.591, \mathrm{p}=0.104$ and $\mathrm{p}=0.191$, respectively, Fig. 1A and B). However, compared with the normal kidney tissues, the RCC tumor tissues exhibited significantly lower TPM1 expression at the mRNA level. Even after the sample number was enlarged to 44 pairs, the statistical difference remained significant $(\mathrm{p}<0.05$, Fig. $1 \mathrm{~A}$ and B).

TPM1 protein levels in the primary RCC tumor tissues were further confirmed by western blotting. The results of the western blotting of the 40 paired RCC samples were consistent with the results of the RT-qPCR. RCC tumor tissue had significantly lower TPM1 expression at the protein level when compared with levels in the normal kidney tissues $(\mathrm{p}<0.01$, Fig. 1C).

Immunohistochemical staining. We then evaluated TPM1 protein expression at the tissue level using immunohistochemical staining of 25 tissue sections, including 25 RCC tissues and 24 paired tumor adjacent tissues (one section only had tumor tissue). In the tumor adjacent tissues, TPM1 was mainly expressed in the cytoplasm of renal tubular cells rather than the nucleus or the renal corpuscle. TPM1 was mainly expressed in the tumor adjacent normal kidney tissues, yet not in the RCC tissues. TPM1 expression was even lost in many highly developed RCC sections. Since ccRCC dominated the majority of RCC cases, we selected one microscopic sample of ccRCC as representative (Fig. 1D). IRS of TPM1 in the RCC tissues was significantly different than that in the adjacent normal renal tissues ( $\mathrm{p}<0.001$, Fig. 1D).

Relationship between the TPM1 mRNA level and the clinical characteristics of the RCC cases. There was no significant difference between age, gender, pathologic type, T and N stage, metastasis, recurrence and alcoholic consumption and TPM1 expression levels among all the patients involved in the RT-qPCR analyses (Table II). TPM1 mRNA expression was significantly decreased in the various types of RCC cases; in other words, there was no significant difference in decreased TPM1 levels among the various RCC subgroups. However, tumor size was significantly associated with the TPM1 mRNA level ( $\mathrm{p}=0.012$, Table II). RCC patients with tumor size $>4.5 \mathrm{~cm}$ had a higher chance to have a downregulated TPM1 level. In addition to tumor size, the association between smoking incidence and TPM1 was also observed ( $\mathrm{p}=0.031$, Table II). 
A

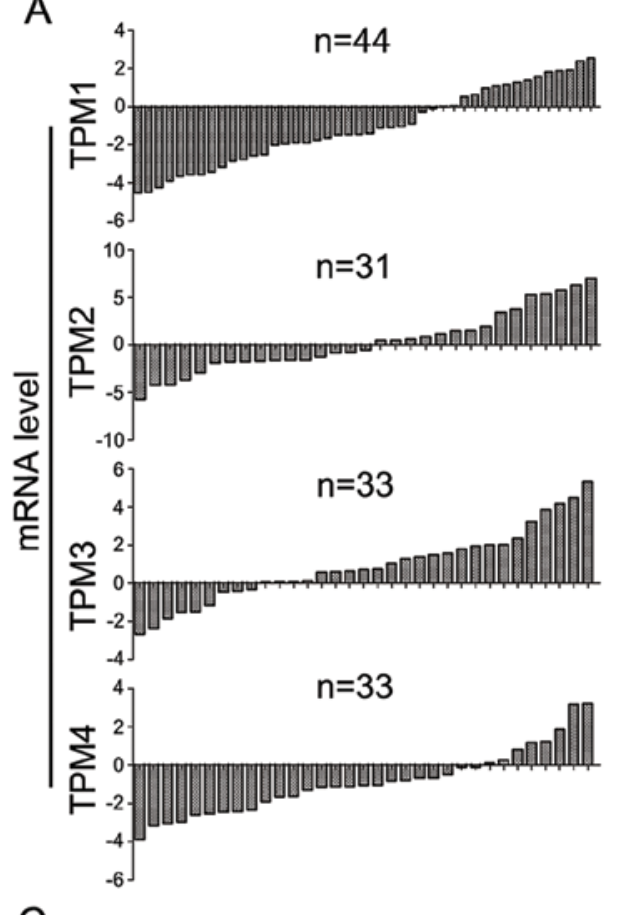

B

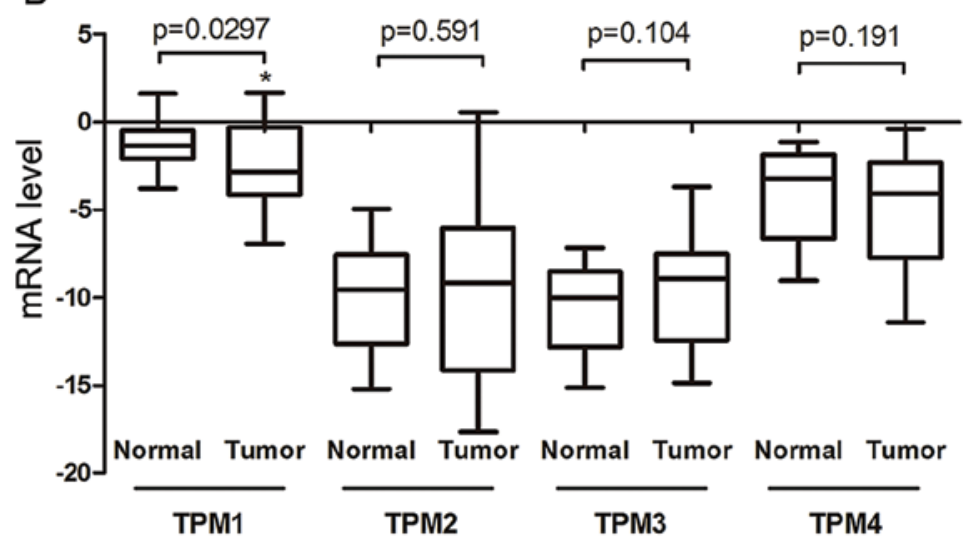

D

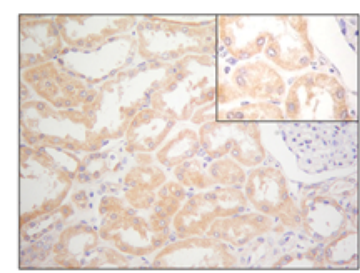

Tumor adjacent tissue

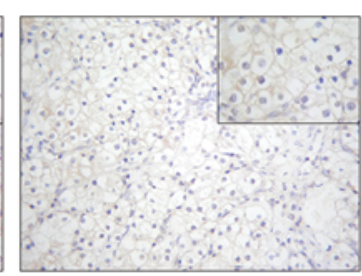

Clear cell carcinoma
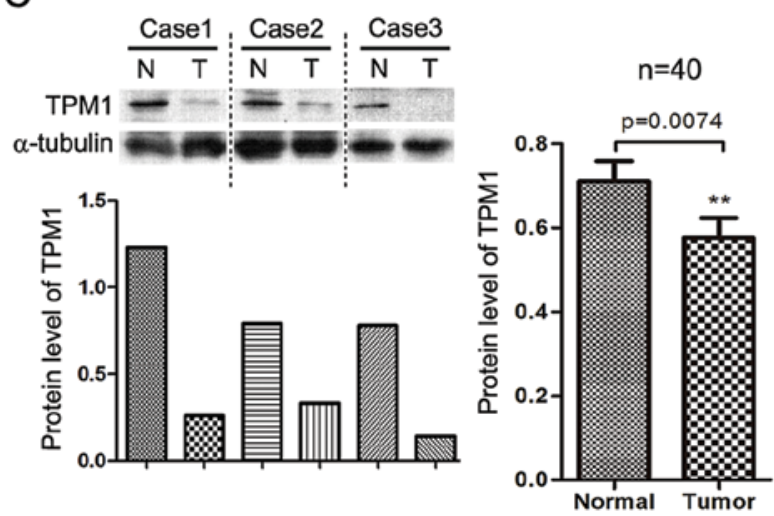

Figure 1. TPM1 expression is downregulated in primary RCC tissues. (A and B) TPM1-4 mRNA expression levels were determined by RT-qPCR in paired RCC tumor tissues and tumor adjacent normal kidney tissues, respectively. (A) Sample pair numbers are provided. GAPDH served as an internal control for the RT-qPCR. (B) Ordinate of the box-whisker plot was calculated as $-\Delta$ Ct. (C) Protein level of TPM1 was detected by western blotting in 40 RCC sample pairs $\alpha$-tubulin served as the internal control. Three pairs of representative western blot bands and corresponding quantitative bars are shown in the left panel. Total average TPM1 protein levels in RCC (T) and paired normal renal (N) tissues are shown in the right panel. (D) Tissue levels of TPM1 expression in 25 RCC sections were analyzed by IHC staining. Representative microphotograph from the RCC pathological subgroup clear cell RCC is presented (upper panel). Reduced by magnification x200. Inserts reduced by magnification x400. Box plots were derived from the different immunohistochemical staining statuses between the central tumor region and the adjacent normal region of 25 primary RCC tissue sections (lower panel). ${ }^{*} \mathrm{p}<0.05,{ }^{* *} \mathrm{p}<0.01,{ }^{* * * *} \mathrm{p}<0.001$ and the exact p-values are indicated above the lines. TPM1, tropomyosin-1; RCC, renal cell carcinoma; IHC, immunohistochemistry.

The markedly decreasing ( $>2$-fold) rate of TPM1 mRNA in the primary RCC cases was $59.1 \%$ (26/44).

TPMI IHC staining and clinical characteristics of the RCC cases. TPM1 IHC staining status in the 25 tissue sections was systematically evaluated. We analyzed the statistical significance of the IRS variances compared to age, gender, grade and stage of the RCC cases. The results indicated that the average IRS in the normal kidney tissues in male and female patients were significantly different from each other $(\mathrm{p}=0.034$, Table III), yet the difference in the IRS for TPM1 in the RCC tumor tissues according to gender was not significant. Notably, the IRS in the normal kidney tissues was significantly decreased with increasing Fuhrman nuclear grade while the IRS in the RCC tissues was significantly increased according to increasing Fuhrman nuclear grade $(\mathrm{p}=0.019$ and $\mathrm{p}=0.009$, Table IV). However, a similar phenomenon was not observed at different clinical stage or age for IRS.

Overall survival and disease-free survival of the RCC patients in regards to TPM1 expression. We followed up 42 of these patients for $>4$ years after surgical intervention in the present study. One patient from the TPM1 increase group passed away from an unrelated cause (myocardial infarction) 629 days after surgery. Thus, this case was treated as a censored observation in the disease-specific survival rate 
Table II. Relationship between the TPM1 mRNA level and the clinical characteristics of the RCC cases.

\begin{tabular}{|c|c|c|c|c|c|}
\hline \multirow[b]{2}{*}{ Characteristics } & \multirow[b]{2}{*}{$\begin{array}{c}\text { No } \\
\text { of pts. } \\
(n=44)\end{array}$} & \multicolumn{2}{|c|}{$\begin{array}{l}\text { Degree of TPM1 } \\
\text { downregulation }\end{array}$} & \multirow[b]{2}{*}{$\chi^{2}$} & \multirow[b]{2}{*}{ P-value } \\
\hline & & $\begin{array}{c}>2 \text {-fold } \\
(\mathrm{n}=26) \\
\mathrm{n}(\%)\end{array}$ & $\begin{array}{c}\leq 2 \text {-fold } \\
(\mathrm{n}=18) \\
\mathrm{n}(\%)\end{array}$ & & \\
\hline \multicolumn{6}{|l|}{ Gender } \\
\hline Male & 25 & $14(56)$ & $11(44)$ & 0.229 & 0.632 \\
\hline Female & 19 & $12(63)$ & $7(37)$ & & \\
\hline \multicolumn{6}{|l|}{ Age (years) } \\
\hline$<55.5$ & 19 & $13(68)$ & $6(32)$ & 3.125 & 0.077 \\
\hline$\geq 55.5$ & 25 & $13(52)$ & $12(48)$ & & \\
\hline \multicolumn{6}{|l|}{ Pathologic type } \\
\hline $\begin{array}{l}\text { ccRCC } \\
\text { nccRCC }\end{array}$ & $\begin{array}{r}39 \\
5\end{array}$ & $\begin{array}{l}21(54) \\
5(100)\end{array}$ & $\begin{array}{c}18(46) \\
0(0)\end{array}$ & 2.229 & $0.135^{\mathrm{c}}$ \\
\hline \multicolumn{6}{|l|}{ Size $(\mathrm{cm})^{\mathrm{a}}$} \\
\hline$\leq 4.5$ & 15 & $5(33)$ & $10(67)$ & 6.246 & 0.012 \\
\hline$>4.5$ & 29 & $21(72)$ & $8(28)$ & & \\
\hline \multicolumn{6}{|l|}{ T stage } \\
\hline $\mathrm{T} 1-\mathrm{T} 2$ & 35 & $21(60)$ & $14(40)$ & 0 & $1^{\mathrm{c}}$ \\
\hline T3-T4 & 9 & $5(56)$ & $4(44)$ & & \\
\hline \multicolumn{6}{|l|}{$\mathrm{N}$ stage } \\
\hline N0 & 42 & $25(60)$ & $17(40)$ & & $1^{\mathrm{b}}$ \\
\hline $\mathrm{N}^{+}$ & 2 & $1(50)$ & $1(50)$ & & \\
\hline \multicolumn{6}{|l|}{ Metastasis } \\
\hline No & 41 & $25(61)$ & $16(39)$ & 0.11 & $0.74^{c}$ \\
\hline Yes & 3 & $1(33)$ & $2(67)$ & & \\
\hline \multicolumn{6}{|l|}{ Recurrence } \\
\hline No & 42 & $26(62)$ & $16(38)$ & & $0.162^{b}$ \\
\hline Yes & 2 & $0(0)$ & $2(100)$ & & \\
\hline \multicolumn{6}{|l|}{ Alcohol } \\
\hline No & 21 & $14(67)$ & $7(33)$ & & $0.121^{\mathrm{b}}$ \\
\hline Yes & 10 & $3(30)$ & $7(70)$ & & \\
\hline No data & 13 & $9(69)$ & $4(31)$ & & \\
\hline \multicolumn{6}{|l|}{ Smoking $^{\mathrm{a}}$} \\
\hline No & 18 & $13(72)$ & $5(28)$ & & $0.031^{\mathrm{b}}$ \\
\hline Yes & 14 & $4(29)$ & $10(71)$ & & \\
\hline No data & 12 & $9(75)$ & $3(25)$ & & \\
\hline
\end{tabular}

Pearson Chi-square test for comparison with all cells $\mathrm{T}>5$ and $\mathrm{N}>40$, otherwise Fisher's exact test or continuity correction were used. ${ }^{\mathrm{a}} \mathrm{p}<0.05$. 'Fisher's exact test was used since $\mathrm{T}$ was $<1$ for $\mathrm{N}$ stage and recurrence while $\mathrm{N}$ was $<40$ for alcohol and smoking. ${ }^{~}$ Continuity correction was used since $1 \leq \mathrm{T}<5$. Pts., patients; TPM1, tropomyosin-1; ccRCC, clear cell renal cell carcinoma; nccRCC, non-clear cell renal cell carcinoma.

analysis while as a death observation in the overall survival rate analysis. During the follow-up, 7 patients $(7 / 27,25.9 \%)$ passed away in the TPM1 decrease group while one unrelated
Table III. Immunoreactive scores for TPM1 according to patient age and gender.

\begin{tabular}{lccccc}
\hline & \multicolumn{2}{c}{ Age (years) } & & \multicolumn{2}{c}{ Gender } \\
\cline { 2 - 3 } \cline { 6 - 6 } Tissues & $<55.5$ & $\geq 55.5$ & & Male & Female \\
\hline Normal & $9.54 \pm 2.73$ & $9.30 \pm 3.02$ & & $10.73 \pm 1.89^{\mathrm{a}}$ & $8.35 \pm 3.02^{\mathrm{a}}$ \\
Tumor & $1.43 \pm 1.59$ & $2.82 \pm 2.71$ & & $2.50 \pm 2.42$ & $1.62 \pm 2.02$ \\
$\Delta$ IRS & $8.11 \pm 3.05$ & $7.05 \pm 4.20$ & & $8.77 \pm 2.97$ & $6.73 \pm 3.79$
\end{tabular}

TPM1, tropomyosin-1; IRS, immunoreactive score.
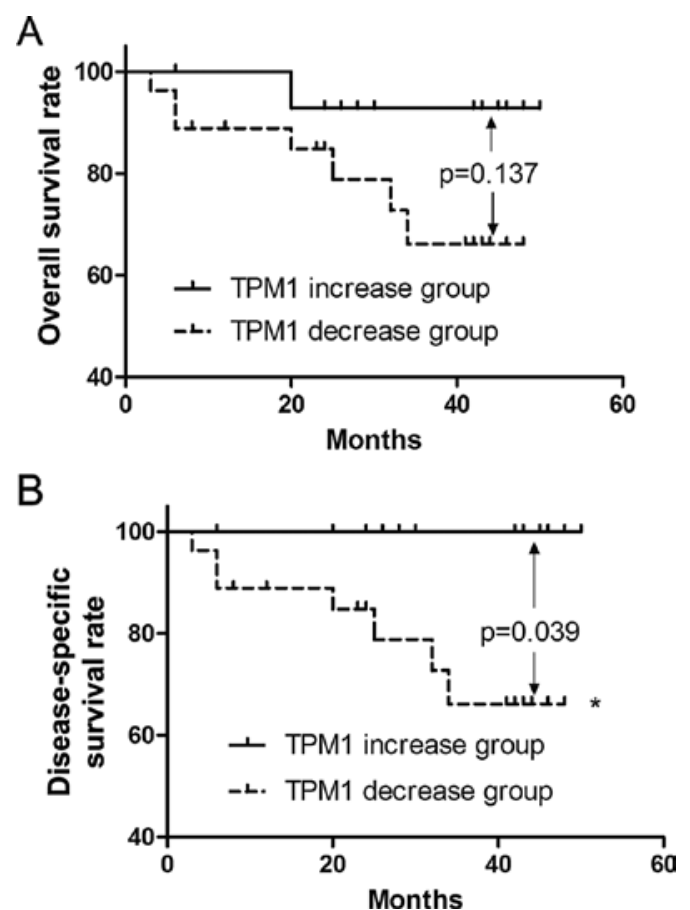

Figure 2. Kaplan-Meier survival curves of the 42 RCC patients. There was no significant difference in the overall survival rates (A), yet a significant difference in the disease-specific survival rates (B) between the TPM1 decrease group $(n=27)$ and the TPM1 increase group $(n=15)$ was observed. Log-rank (Mantel-Cox) test was used to detect the survival rate difference between the two TPM1 expression groups. ${ }^{*} \mathrm{p}<0.05$ and the exact $\mathrm{p}$-values are indicated between the two lines in the graphs. RCC, renal cell carcinoma; TPM1, tropomyosin-1.

death $(1 / 15,6.7 \%)$ occurred in the TPM1 increase group. No significant difference was observed in regards to the overall survival rate ( $p=0.137$, Fig. $2 \mathrm{~A}$ ), yet a significant difference in the disease-specific survival rate was noted between the TPM1 decrease group and TPM1 increase group ( $p=0.039$, Fig. $2 B$ ).

Scratch and Transwell migration assays. TPM1 also played a role in RCC cell motility. In the scratch assay, the TPM1transfected OSRC-2 and 786-O cells exhibited significantly slower wound healing compared with the empty plasmid transfected and the mock treatment group. In regards to the OSRC-2 cells, the wound healing status between the experimental and the negative control group showed a significant difference after $48 \mathrm{~h}(\mathrm{p}=0.0292$, Fig. 3B and C). The same 
Table IV. Immunoreactive scores for TPM1 according to different grade and stage.

\begin{tabular}{|c|c|c|c|c|c|c|}
\hline \multirow[b]{2}{*}{ Tissues } & \multicolumn{3}{|c|}{ Fuhrman nuclear grade } & \multicolumn{3}{|c|}{ TNM stage } \\
\hline & I & II & III & I & II & $\mathrm{III}^{\mathrm{c}}$ \\
\hline Normal & $12.00 \pm 0^{\mathrm{a}}$ & $9.44 \pm 2.54^{\mathrm{a}}$ & $6.00 \pm 2.65^{\mathrm{a}}$ & $9.33 \pm 0.64$ & $9.25 \pm 0.75$ & $12.00 \pm 0$ \\
\hline Tumor & $1.13 \pm 0.25$ & $2.14 \pm 2.15$ & $2.67 \pm 4.19$ & $1.83 \pm 0.41$ & $3.83 \pm 2.40$ & $1.00 \pm 0$ \\
\hline$\Delta \mathrm{IRS}$ & $10.86 \pm 0.25^{\mathrm{b}}$ & $7.68 \pm 3.37^{\mathrm{b}}$ & $3.33 \pm 1.76^{\mathrm{b}}$ & $7.50 \pm 0.80$ & $7.75 \pm 1.75$ & $11.00 \pm 0$ \\
\hline
\end{tabular}

Kruskal-Wallis test for global comparison among grades and stages. ${ }^{\mathrm{a}} \mathrm{p}<0.05,{ }^{\mathrm{b}} \mathrm{p}<0.01$. ${ }^{\mathrm{c}}$ Only one tissue section was stage III. TPM1, tropomyosin-1; TNM, tumor-node-metastasis.

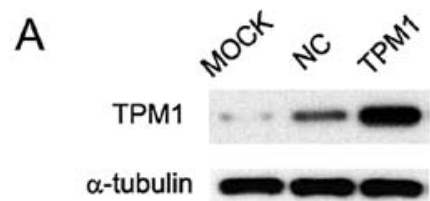

C $\quad 48 \mathrm{~h}$ after scratch

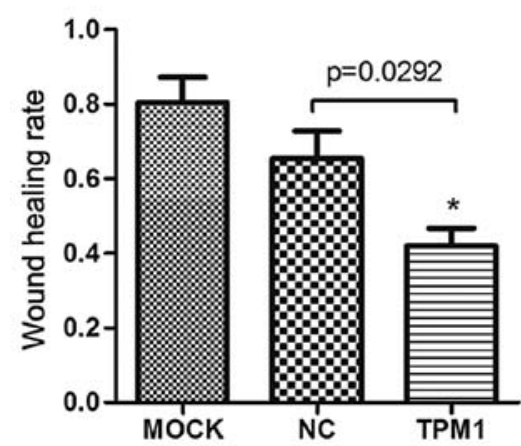

D

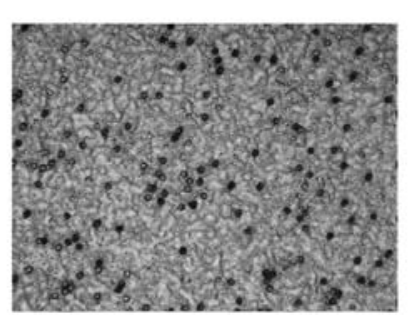

B<smiles>C1CCCCC1</smiles>
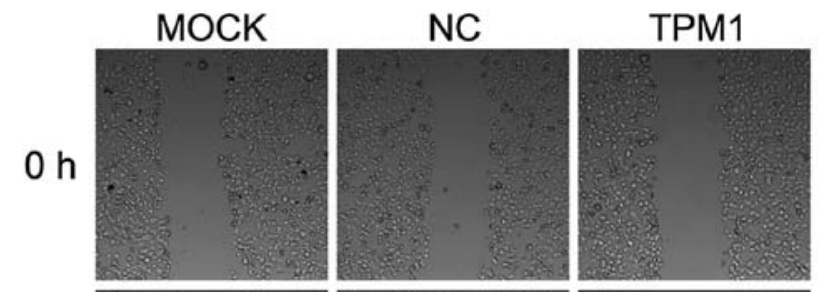

$24 \mathrm{~h}$
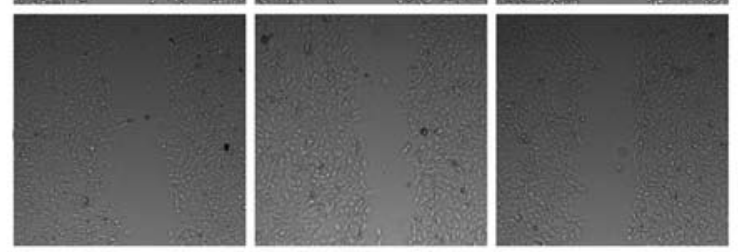

$48 \mathrm{~h}$
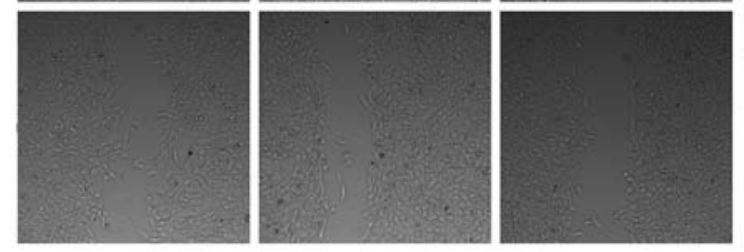

E

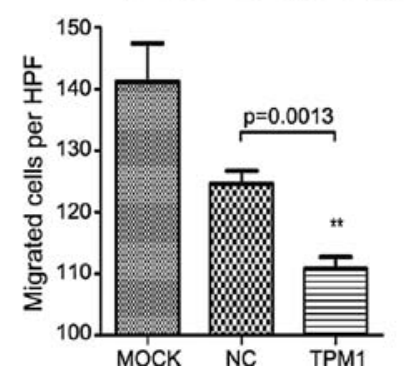

$\mathrm{F}$

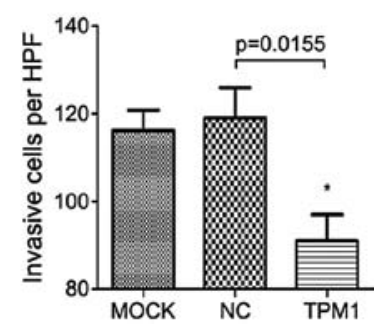

Figure 3. Tumor-suppressive functions of TPM1 were observed using OSRC-2 cell (ccRCC) experiments. Cells were transfected with the TPM1-encoding plasmid (pc3.1-TPM1), the empty plasmid (pc3.1-NC) or no plasmid (mock). (A) The TPM1 protein level in the OSRC-2 cells was detected using western blotting $48 \mathrm{~h}$ after transfection. (B and C) The scratch assay revealed that TPM1 inhibited the migration of the OSRC-2 cells. Images of the cell monolayers were captured at 0,24 and $48 \mathrm{~h}$ after scratching; representative images are shown in B. The wound healing rate was calculated as newly covered area at the indicated time compared with the initial whole uncovered area. (C) Values are the mean \pm SD of 5 randomly selected zones. (D-F) The Transwell migration and invasion assays revealed that TPM1 inhibited both the migratory and invasive abilities of the OSRC-2 cells. (D) Cells migrating or invading through the Transwell membrane were fixed and stained with crystal violet. ( $\mathrm{E}$ and $\mathrm{F}$ ) Values of the bars are the mean \pm SD of cell numbers in 5 randomly selected high power fields (magnification, $\mathrm{x} 200$ ). ${ }^{*} \mathrm{p}<0.05,{ }^{* *} \mathrm{p}<0.01$ and the exact p-values are indicated above the lines. TPM1, tropomyosin-1; ccRCC, clear cell renal cell carcinoma.

observation was made in the $786-\mathrm{O}$ cells until $24 \mathrm{~h}$ after scratching ( $\mathrm{p}=0.0016$, Fig. $4 \mathrm{~B}$ and $\mathrm{C}$ ); a near complete wound closure was observed after $48 \mathrm{~h}$. This was probably due to the weaker migratory ability of the OSRC-2 compared to the 786-O cells.

Correspondingly, the Transwell migration assay demonstrated that overexpression of TPM1 was associated with markedly inhibited migration in both the OSRC-2 and 786-O cells ( $p=0.0013$ and $p=0.0039$ separately, Figs. 3E and 4E). Cell migration was detected by crystal violet staining and microscopic graphs $24 \mathrm{~h}$ after seeding into the Transwell inserts. In regards to the OSRC-2 cells, the number of migrated cells/ microscopic field (x200) for the pc3.1-NC and pc3.1-TPM1 groups was $124.6 \pm 2.112$ and $110.8 \pm 1.934$, respectively. In regards to the 786-O cells, the two values for each group were $125.0 \pm 2.168$ and $108.2 \pm 3.597$, respectively. 
A

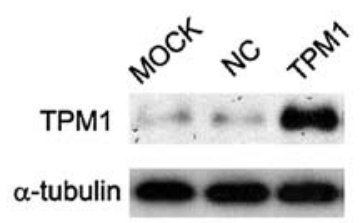

C

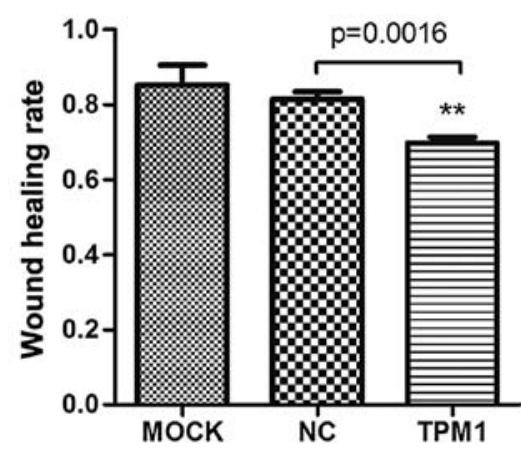

D

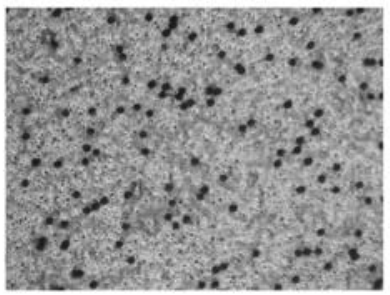

B MOCK

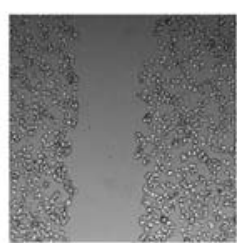

$24 \mathrm{~h}$
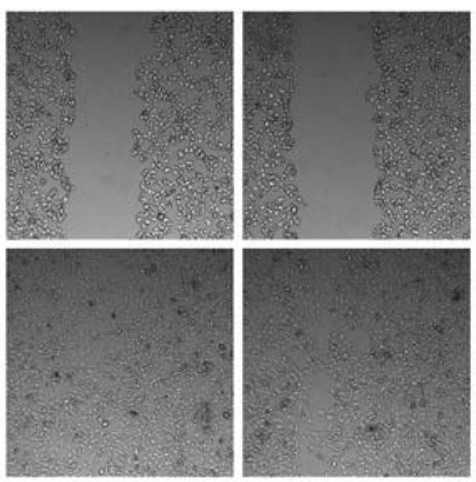

NC
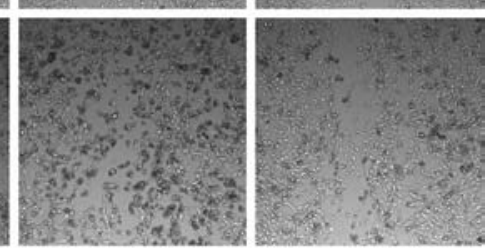

$\mathrm{F}$

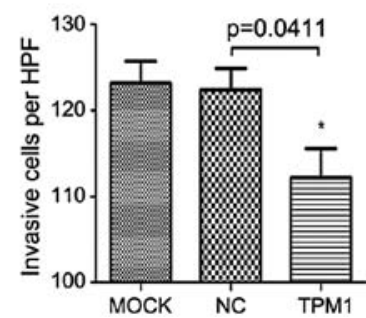

Figure 4. Tumor-suppressing functions of TPM1 were observed through 786-O (RCC) cell experiments. Cells were transfected with the TPM1-encoding plasmid (pc3.1-TPM1), the empty plasmid (pc3.1-NC) or no plasmid (mock). (A) The TPM1 protein level in the 786-O cells was detected using western blotting $48 \mathrm{~h}$ after transfection. (B and C) The scratch assay revealed that TPM1 inhibited the migration of the 786-O cells. Images of the cell monolayers were captured at 0,24 and $48 \mathrm{~h}$ after scratching; representative images are shown in B. The wound healing rate was calculated as newly covered area at the indicated time compared with the initial whole uncovered area. (C) Values are the mean \pm SD of 5 randomly selected zones. (D-F) The Transwell migration and invasion assays revealed that TPM1 inhibited both the migratory and invasive abilities of the 786-O cells. (D) Cells migrating or invading through the Transwell membrane were fixed and stained with crystal violet. (E and F) Values of the bars are the mean \pm SD of cell numbers in 5 randomly selected high power fields (x200). ${ }^{*} \mathrm{p}<0.05,{ }^{* *} \mathrm{p}<0.01$ and the exact $\mathrm{p}$-values are indicated above the lines. TPM1, tropomyosin-1; RCC, renal cell carcinoma.

For the Transwell invasion assay, the cells needed to invade the Matrigel matrix and then reach the filter bottom which was stained and then images could be captured. Compared with the negative control group, the invasive abilities of the OSRC-2 and 786-O cells in the TPM1-transfected group were significantly reduced $(p=0.0155$ and $p=0.0411$ for each cell type, Figs. 3F and 4F). In regards to the OSRC-2 cells, the numbers of invasive cells/microscopic field (x200) in the pc3.1-NC and pc3.1-TPM1 groups were 119.0 \pm 6.928 and $91 \pm 5.958$, respectively. In regards to the 786-O cells, the two values for each of the pc3.1 groups were 122.4 \pm 2.502 and 112.2 \pm 3.367 , respectively.

Analysis of apoptosis. We then detected apoptosis in the OSRC-2 and 786-O cells following TPM1 transfection. For these two cell lines, we used flow cytometry based on Annexin V and PI staining. The results demonstrated that TPM1 transfection promoted cell apoptosis in these two RCC cell lines (Figs. 5 and 6). At $72 \mathrm{~h}$ after transfection, the early stage apoptosis rate (Annexin $\mathrm{V}^{+} / \mathrm{PI}^{-}$) following TPM1 transfection was $4.1 \pm 0.2$ and $3.8 \pm 0.2 \%$ for the OSRC-2 and 786-O cells, respectively. This was significantly higher than the negative control: $1.7 \pm 0.4$ and $2.4 \pm 0.4 \%$, respectively $(p=0.0051$ and $p=0.0361$, Figs. 5B and 6B). In addition, the total apoptosis rate (Annexin $\mathrm{V}^{+} / \mathrm{PI}^{ \pm}$) following TPM1 transfection was $6.0 \pm 0.2$ and $5.8 \pm 0.3 \%$ for the OSRC-2 and 786-O cells, respectively. This was also significantly higher than the empty vector transfection: $2.3 \pm 0.5$ and $4.2 \pm 0.4 \%$, respectively $(\mathrm{p}=0.0022$ and $\mathrm{p}=0.0318$, Figs. 5C and 6C).

\section{Discussion}

Recently, it was reported that TPM1 acts as a tumorsuppressor gene (TSG) and is downregulated in various types of cancers (6,12-16). However, the existence of other TPM family members varied among the different types of cancers or studies (17-19). In the present study, TPM1 was significantly downregulated in most RCC tissues compared to that in the tumor adjacent normal renal tissues while TPM2-4 showed no significant expression differences in the RCC tissue samples. These results indicated that TPM1, among all of the TPM family members, was specifically downregulated in the various primary RCC patients. In addition, post-transcriptional regulation mechanisms may be involved in the carcinogenesis of RCC since some samples had inconsistent TPM1 expression between the mRNA and protein level. 


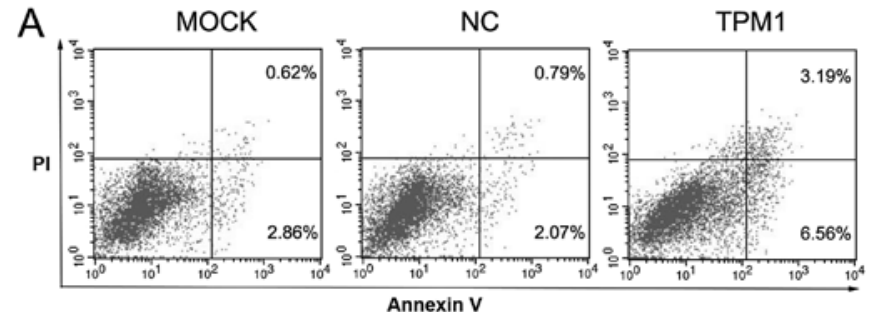

B

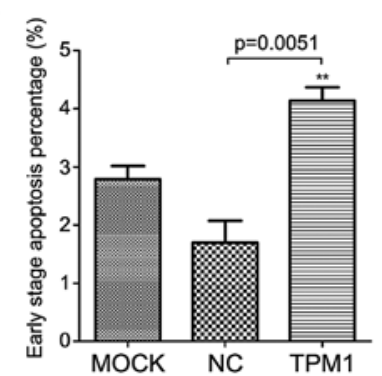

$\mathrm{C}$

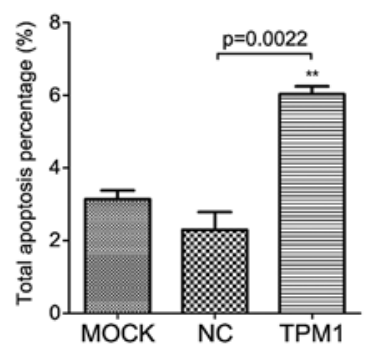

Figure 5. TPM1 overexpression enhances the apoptosis of OSRC-2 cells. Cells were transfected with the TPM1-encoding plasmid (pc3.1-TPM1), the empty plasmid (pc3.1-NC) or no plasmid (mock). (A) 2D scatter plot of one example set of samples. (B and C) Results demonstrated that pc3.1-TPM1 transfection for $72 \mathrm{~h}$ significantly enhanced both the early stage (Annexin $\mathrm{V}^{+} /$ $\mathrm{PI}^{-}, \mathrm{p}=0.0051$ ) and the overall stages (Annexin $\mathrm{V}^{+} / \mathrm{PI}^{+}$and Annexin $\mathrm{V}^{+} / \mathrm{PI}^{-}$, $\mathrm{p}=0.0022$ ) of apoptosis in the OSRC- 2 cells. The values indicated by the bars are the mean \pm SD of the cell percentages from 3 parallel experiments ${ }^{* *} \mathrm{p}<0.01$ and the exact $\mathrm{p}$-values are indicated above the lines. TPM1, tropomyosin-1.

Importantly, decreased TPM1 expression occurred in all types of RCC, such as ccRCC, chRCC or other RCC, and was also associated with a larger tumor size, a lower Fuhrman nuclear grade, and poorer prognosis after operation. This suggests that downregulation of TPM1 may be an early event during RCC clinical development excluding renal mass growth. We also speculated that TPM1 plays an important role during the pathological progression of RCC, for example, in the process of atypical nuclear progression. Many studies have confirmed that Fuhrman grade is correlated with RCC prognosis (20). Recent research found that the Fuhrman grade also provides independent prognostic information for papillary RCC patients (21). We found that TPM1 expression was associated synchronously with both the Fuhrman grade and prognosis in the participating RCC patients. Thus, we inferred that downregulation of TPM1 in RCC may be an independent risk factor for poor prognosis. However, this prediction may be more complicated since IRS could only be semi-quantified. Due to the limited number of patients involved in the present study, a statistically significant association between TPM1 expression and risk of metastasis could not be observed, which was supported by previous studies. Further study with a large number of participants and an improved study design should be conducted to further confirm our prediction.

As a TSG, TPM1 has various roles in RCC tumor cells. After TPM1 was restored in OSRC-2 and 786-O cells, the most significant observation was that the migratory and invasive capabilities of the RCC cells were reduced. This discovery confirmed many previous studies by other researchers $(6,22,23)$. In addition, our observation confirmed the apoptotic function of TPM1 in RCC cell lines $(6,24)$.

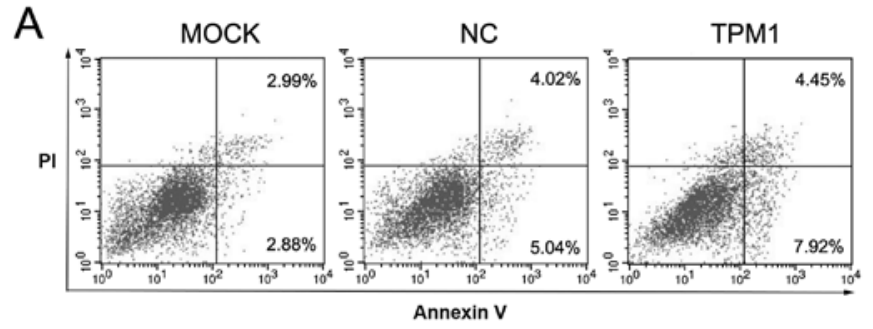

B

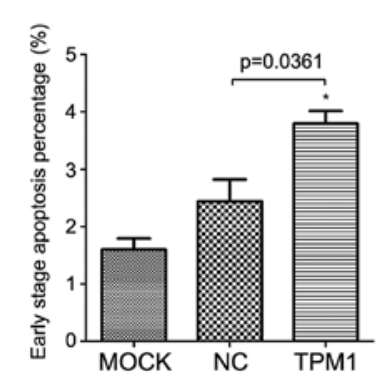

$\mathrm{C}$

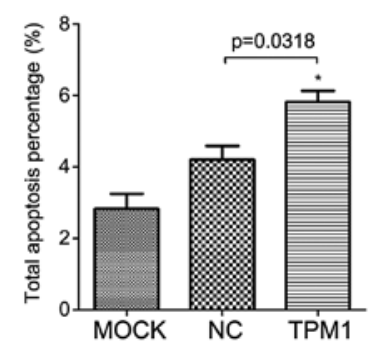

Figure 6. TPM1 overexpression enhances the apoptosis of 786-O cells. Cells were transfected with the TPM1-encoding plasmid (pc3.1-TPM1), the empty plasmid (pc3.1-NC) or no plasmid (mock). (A) 2D scatter plot of one example set of samples. (B and C) Results demonstrated that pc3.1-TPM1 transfection for $72 \mathrm{~h}$ significantly enhanced both the early stage (Annexin $\mathrm{V}^{+}$/ $\mathrm{PI}^{-}, \mathrm{p}=0.0361$ ) and the overall stages (Annexin $\mathrm{V}^{+} / \mathrm{PI}^{+}$and Annexin $\mathrm{V}^{+} / \mathrm{P}^{-}$, $\mathrm{p}=0.0318$ ) of apoptosis in the OSRC -2 cells. The values indicated by the bars are the mean $\pm \mathrm{SD}$ of the cell percentage from 3 parallel experiments. ${ }^{*} \mathrm{p}<0.05$ and the exact p-values are indicated above the lines. TPM1, tropomyosin-1.

Many other meaningful studies have demonstrated that microRNA-21 suppresses TPM1, a target gene of microRNA-21, along with other target genes, such as PDCD4 and $\operatorname{MMP}(7,8,23)$. MicroRNA-21 has been the most frequently researched microRNA in solid tumors and has been already shown to be upregulated in RCC (25). Therefore, it is reasonable to speculate that microRNA-21 plays a regulatory role in TPM1 expression during RCC promotion. In addition, researchers also found that many epigenetic regulatory processes, such as promoter methylation $(6,18)$, and chromatin remodeling caused by histone deacetylation (16), are involved in the regulation of TPM1 in other types of cancers other than RCC. Further research regarding these genetic modifications specifically in RCC needs to be conducted.

\section{Acknowledgements}

This study was supported by the National Nature Science Foundation of China (31100999 and 31071131). In the present study, human kidney cancer tissues were stored by Dr Jing Jiang in the Tissue Warehouse of the First Hospital, Jilin University. Professor Shunzi Jin from the Public Health College of Jilin University provided the laboratory to complete the cell experiments. Professor Shibo Li from the Pediatrics Department of the Health Science Center, University of Oklahoma, provided assistance with language editing.

\section{References}

1. Jemal A, Bray F, Center MM, Ferlay J, Ward E and Forman D: Global cancer statistics. CA Cancer J Clin 61: 69-90, 2011. 
2. Mihaly Z, Sztupinszki Z, Surowiak P and Gyorffy B: A comprehensive overview of targeted therapy in metastatic renal cell carcinoma. Curr Cancer Drug Targets 12: 857-872, 2012.

3. Pittenger MF, Kazzaz JA and Helfman DM: Functional properties of non-muscle tropomyosin isoforms. Curr Opin Cell Biol 6: 96-104, 1994.

4. Brown JH, Kim KH, Jun G, et al: Deciphering the design of the tropomyosin molecule. Proc Natl Acad Sci USA 98: 8496-8501, 2001.

5. Perry SV: Vertebrate tropomyosin: distribution, properties and function. J Muscle Res Cell Motil 22: 5-49, 2001.

6. Bharadwaj S and Prasad GL: Tropomyosin-1, a novel suppressor of cellular transformation is downregulated by promoter methylation in cancer cells. Cancer Lett 183: 205-213, 2002.

7. Mlakar V, Berginc G, Volavsek M, Stor Z, Rems M and Glavac D: Presence of activating KRAS mutations correlates significantly with expression of tumour suppressor genes $D C N$ and TPMI in colorectal cancer. BMC Cancer 9: 282, 2009.

8. Zhu S, Si ML, Wu H and Mo YY: MicroRNA-21 targets the tumor suppressor gene tropomyosin 1 (TPM1). J Biol Chem 282: 14328-14336, 2007.

9. Wang Y, Zhang R, Wu D, et al: Epigenetic change in kidney tumor: downregulation of histone acetyltransferase MYST1 in human renal cell carcinoma. J Exp Clin Cancer Res 32: 8, 2013.

10. Venerito M, Treiber G, Wex T, et al: Effects of low-dose aspirin on gastric erosions, cyclooxygenase expression and mucosal prostaglandin- $\mathrm{E}_{2}$ do not depend on Helicobacter pylori infection. Aliment Pharmacol Ther 23: 1225-1233, 2006.

11. Dong W, Zhang H, Li J, et al: Estrogen induces metastatic potential of papillary thyroid cancer cells through estrogen receptor $\alpha$ and $\beta$. Int J Endocrinol 2013: 941568, 2013.

12. Petrova DT, Asif AR, Armstrong VW, et al: Expression of chloride intracellular channel protein 1 (CLIC1) and tumor protein D52 (TPD52) as potential biomarkers for colorectal cancer. Clin Biochem 41: 1224-1236, 2008.

13. $\mathrm{Ku} \mathrm{BM}$, Ryu HW, Lee YK, et al: 4'-Acetoamido-4-hydroxychalcone, a chalcone derivative, inhibits glioma growth and invasion through regulation of the tropomyosin 1 gene. Biochem Biophys Res Commun 402: 525-530, 2010.

14. Yager ML, Hughes JA, Lovicu FJ, Gunning PW, Weinberger RP and O'Neill GM: Functional analysis of the actin-binding protein, tropomyosin 1, in neuroblastoma. Br J Cancer 89: 860-863, 2003.
15. Alaiya AA, Oppermann M, Langridge $\mathrm{J}$, et al: Identification of proteins in human prostate tumor material by two-dimensional gel electrophoresis and mass spectrometry. Cell Mol Life Sci 58: 307-311, 2001.

16. Yang W, Wang X, Zheng W, Li K, Liu H and Sun Y: Genetic and epigenetic alterations are involved in the regulation of TPM1 in cholangiocarcinoma. Int J Oncol 42: 690-698, 2013.

17. Tang HY, Beer LA, Tanyi JL, Zhang R, Liu Q and Speicher DW: Protein isoform-specific validation defines multiple chloride intracellular channel and tropomyosin isoforms as serological biomarkers of ovarian cancer. J Proteomics 89: 165-178, 2013.

18. Zare M, Jazii FR, Soheili ZS and Moghanibashi MM: Downregulation of tropomyosin-1 in squamous cell carcinoma of esophagus, the role of Ras signaling and methylation. Mol Carcinog 51: 796-806, 2012.

19. Pawlak G, McGarvey TW, Nguyen TB, et al: Alterations in tropomyosin isoform expression in human transitional cell carcinoma of the urinary bladder. Int J Cancer 110: 368-373, 2004.

20. Ficarra V, Martignoni G, Maffei N, et al: Original and reviewed nuclear grading according to the Fuhrman system: a multivariate analysis of 388 patients with conventional renal cell carcinoma. Cancer 103: 68-75, 2005.

21. Klatte T, Anterasian C, Said JW, et al: Fuhrman grade provides higher prognostic accuracy than nucleolar grade for papillary renal cell carcinoma. J Urol 183: 2143-2147, 2010.

22. Lees JG, Bach CT and O'Neill GM: Interior decoration: tropomyosin in actin dynamics and cell migration. Cell Adh Migr 5: 181-186, 2011.

23. Zhu S, Wu H, Wu F, Nie D, Sheng S and Mo YY: MicroRNA-21 targets tumor suppressor genes in invasion and metastasis. Cell Res 18: 350-359, 2008.

24. Bharadwaj S, Thanawala R, Bon G, Falcioni R and Prasad GL: Resensitization of breast cancer cells to anoikis by tropomyosin-1: role of Rho kinase-dependent cytoskeleton and adhesion. Oncogene 24: 8291-8303, 2005.

25. Faragalla H, Youssef YM, Scorilas A, et al: The clinical utility of miR-21 as a diagnostic and prognostic marker for renal cell carcinoma. J Mol Diagn 14: 385-392, 2012. 